Published in final edited form as:

Cytokine Growth Factor Rev. 2013 February ; 24(1): 51-57. doi:10.1016/j.cytogfr.2012.07.002.

\title{
Emerging role of Interleukin-22 in autoimmune diseases
}

\author{
Hai-Feng Pan ${ }^{1,2}$, Xiang-Pei $\mathrm{Li}^{3}$, Song Guo Zheng ${ }^{4,}$, and Dong-Qing $\mathrm{Ye}^{1,2,{ }^{*}}$ \\ ${ }^{1}$ Department of Epidemiology and Biostatistics, School of Public Health, Anhui Medical University, \\ Hefei, China \\ ${ }^{2}$ Anhui provincial laboratory of population health \& major disease screening and diagnosis, Anhui \\ Medical University, Hefei, China \\ ${ }^{3}$ Department of Rheumatology, Anhui Provincial Hospital, Hefei, China \\ ${ }^{4}$ Division of Rheumatology/Immunology, Department of Medicine, University of Southern \\ California
}

\begin{abstract}
Interleukin-22 (IL-22) is an IL-10 family cytokine member that was recently discovered to be mainly produced by Th17 cells. Previous studies have indicated the importance of IL-22 in host defense against Gram-negative bacterial organisms (in gut and lung). Recently, there is emerging evidence that IL-22 is involved in the development and pathogenesis of several autoimmune diseases, such as systemic lupus erythematosus (SLE), rheumatoid arthritis (RA), multiple sclerosis (MS), Sjögren's syndrome (SS) and psoriasis. Therapeutics targeting IL-22 therefore may have promise for treating various autoimmune diseases. In this review, we discuss the recent progression of the involvement of IL-22 in the development and pathogenesis of autoimmune diseases, as well as its clinical implications and therapeutic potential.
\end{abstract}

\section{Keywords}

IL-22; Th17; Th22; autoimmune; therapeutic

\section{Introduction}

Unregulated T-cell responses or overwhelming cytokines secreted by $\mathrm{T}$ cells and other cell sources are associated with many autoimmune diseases such as systemic lupus erythematosus (SLE), rheumatoid arthritis (RA), multiple sclerosis (MS), Sjögren's

\footnotetext{
(C) 2012 Elsevier Ltd. All rights reserved.

*Correspondence: Dong-Qing Ye, M.D, Department of Epidemiology and Biostatistics, School of Public Health, Anhui Medical University, 81 Meishan Road, Hefei, Anhui, 230032, PR China, ydq@ahmu.edu.cn, Tel: +86 551 5167726; Fax: +86 551 5161171 or Song GuoZheng, M.D., Ph.D, Department of Medicine, Keck School of Medicine, University of Southern California, szheng@usc.edu, Tel: 323442 2128; Fax: 3234422874.

Declaration of interest statement: None declared

Publisher's Disclaimer: This is a PDF file of an unedited manuscript that has been accepted for publication. As a service to our customers we are providing this early version of the manuscript. The manuscript will undergo copyediting, typesetting, and review of the resulting proof before it is published in its final citable form. Please note that during the production process errors may be discovered which could affect the content, and all legal disclaimers that apply to the journal pertain.
} 
syndrome (SS) and psoriasis. Interleukin-22 (IL-22) is a cytokine produced by several different cellular sources including Th17 cells [1, 2], natural killer (NK) 22 cells [3], and Th22 cells $[4,5]$. Recently, numerous studies regarding the role of IL-22 in autoimmune diseases are emerging, and several reports suggest that IL-22 plays a critical role in the inflammation and proliferation cascade of various autoimmune diseases like SLE [6-11], RA [12-16], MS [17-19], SS [20, 21] and psoriasis [22, 23]. In this review, we summarize our current understanding of the involvement of IL-22 in the development and pathogenesis of autoimmune diseases, as well as its clinical implications and therapeutic potential.

\section{IL-22 and IL-22R}

IL-22 is an IL-10 family cytokine member, being initially recognized as IL-10-related Tcell-derived inducible factor (IL-TIF) [24]. It is induced in mouse T lymphoma cells by IL-9 and has $22 \%$ amino acid identity with IL-10 [25]. IL-TIF does not appear to have the effects on the proliferation of T cells or mast cells; however, it does activate STAT3 in mesangial cells [25]. Human IL-22 protein is 146 amino acids in length and has $80.8 \%$ identity with murine IL-22. Like other IL-10 family members, IL-22 also has an a-helical secondary structure [26]. The IL-22 receptor (IL-22R) belongs to the class II cytokine receptor family and consists of two subunits, IL-22R1 and IL-10R2 (also called IL10RB) [26, 27]. IL-22R1 expression is present in a variety of nonimmunetissues: skin, lung, kidney, pancreas, etc., while IL-10R2 is widely expressed on immune cells (T, B and NK cells) [27]. There is also a soluble IL-22R called IL-22-binding protein (IL-22BP), which is encoded by another gene, and this protein has been shown to counteract IL-22 binding in vitro [26, 27]. The affinity of IL-22 to IL-22BP is at least four times higher than that of IL-22 to IL-22R1 [28].

\section{Cellular sources of IL-22}

A broad variety of lymphocytes secrete IL-22 (Table 1). IL-22 was originally thought to be a Th1-associated cytokine, it is now recognized that IL-22 is highly expressed by IL-17producing cells, called Th17 cells [2]. However, the optimal conditions for secretion of IL-17A or IL-22 by Th17 cells are different, as do the transcription factors involved. Unlike IL-17A expression, which requires both TGF- $\beta$ and a secondary inflammatory stimulus including IL-6, IL-21 or IL-23, IL-22 expression can be induced solely by IL-6 [23]. Furthermore, increasing levels of TGF- $\beta$ that allow for high IL-17A expression lead to a reduction in IL-22 levels [23, 29]. This divergence is partly explained by the recent discovery of the transcription factor aryl hydrocarbon receptor (AHR), whose ligands enhance Th17 cytokine production, but have more robust effects on IL-22 secretion compared with IL-17A [30]. Most importantly, AHR is essential for IL-22 expression, but not for the expression of IL-17A and other Th17 cytokines. In addition to Th17 cells, IL-22 is also expressed by other immune cell subsets. Th22 cells, a subset of CD4 T cells that specifically expresses IL-22 and is mainly found in tissues, produce IL-22 in response to IL-6 and tumor necrosis factor a (TNF-a), particularly in the skin [31]. Th22 T-cell clones appear to be very stable; when cultured in Th1-, Th2-, Th17- or Treg-polarizing conditions, the Th22 clones continue to express IL-22 but not the other cytokines associated with these Th subsets [32]. $\gamma \delta \mathrm{T}$ cells, a subset of T-cells which expresses a $\gamma \delta \mathrm{TCR}$, produce IL-22 in response to IL-23, IL-22- expressing $\gamma \delta T$ cells are particularly important in pulmonary 
immune responses [33]. NK cells produce IL-22 in response to IL-12 and IL-18 or IL-23 [3, 34, 35]. In addition, Retinoic acid-related orphan receptor $\gamma \mathrm{t}$-positive $(\mathrm{ROR} \gamma \mathrm{t}+)$ innate lymphoid cells, including lymphoid tissue inducer (LTi) and LTi-like cells also express IL-22, LTi-like cells express low constitutive levels of IL-22 that are highly induced upon activation by IL-23 stimulation [36, 37]. (Table 1)

\section{Signaling pathways of IL-22}

IL-22 binds as a homodimer at a receptor complex composed of the IL-10R2 and the IL-22R1. IL-22BP acts as a natural, soluble antagonist. IL-22 binding to IL-22R complex induces a cascade of downstream signaling pathways [38]. The initial studies using a murine kidney cell line demonstrated that IL-22R ligation induced STAT3 phosphorylation, and to a lesser extent, STAT5 phosphorylation [25], while other studies reported the phosphorylation of STAT1, STAT3 and STAT5 in a human kidney cell line [39]. A latter study further revealed that IL-22 signaling utilizes Jak1 and Tyk2 to propagate downstream phosphorylation signals, including MAPK signaling pathways (ERK1/2, MEK1/2, JNK, and p38 kinase), STAT1, STAT3, and STAT5 [40]. Although STAT3-mediated signaling is a common pathway shared by the IL-10 cytokine family members, IL-22 signaling exhibits several distinct properties. For instance, compared with IL-10 stimulation that induces phosphorylation of tyrosine residues on STAT3, IL-22 stimulation induces STAT3 phosphorylation on both tyrosine and serine residues, and also strongly activates the ERK1/2 pathway [40]. Because both IL-22 and IL-10 utilize IL-10R2, Jak1, and Tyk2, the differences in signal transduction pathways may be attributed to differences between IL-22R1 and IL-10R1 [41]. The phosphorylation of STAT3 is an essential pathway in mediating the effects of IL-22 on epithelial cells at barrier surfaces, as phosphorylation of STAT3 in intestinal epithelial cells following chemical-induced colitis is IL-22-dependent; additionally, conditional deletion of epithelial-intrinsic STAT3 from intestinal epithelial cells mimicked that in IL-22 deficient mice during chemical-induced colitis, implicating a requirement for STAT3 in IL-22-mediated signaling in vivo [42]. All these studies above suggest that similar to other members of the IL-10 cytokine family, IL-22 utilizes Jak-STAT signaling, mainly through STAT3; however, several differences also exist between IL-22 and other IL-10 family members, including differential activation of MAPK pathways and phosphorylation of STAT3 on tyrosineand serine residues (Fig. 1). [40][40] The IL-22 signaling pathways affect multiple molecular processes in autoimmune diseases [43-47], therefore, manipulation of IL-22 and its signaling pathways may have the potential to provide treatments for autoimmune diseases.

\section{IL-22 in autoimmune diseases}

Autoimmune diseases are characterized by the impaired function and the destruction of tissues that are caused by an immune response in which abnormal antibodies are produced and attacked the body's own cells and tissues. Although there is significant progress in the development of new treatment modalities, the long-term outcome is often poor for many of the affected patients $[48,49]$. Therefore, a better understanding of the pathogenesis of the autoimmune diseases is needed. The spectrum of autoimmune diseases includes a large variety of diseases such as SLE, RA, MS, SS and psoriasis displaying different clinical 
features. Besides the significant clinical differences, there are also many clinical features and pathogenic mechanisms overlaps among these autoimmune diseases. For example, SLE, RA, SS, and psoriasis share chronic inflammatory joint disease, and SLE and SS share comparable cardiac pathologies [50].

Studies have revealed that many inflammatory cytokines and chemokines are involved in the pathogenesis of these autoimmune diseases. It is well established that in the presence of the common inflammatory cytokine IFN- $\gamma$, local antigen-presenting cells (APCs) produce IL-12 leading to differentiation of CD4+ T cells into IFN- $\gamma$-secreting Th1 cells. In contrast, in the presence of IL-4, CD4+ T cells preferentially develop into IL-4-, IL-5-, and IL-13-producing Th2 cells. Th1 dominant immune responses have been commonly considered to be pathological in autoimmune diseases via the induction of inflammatory reaction. However, recently, there is compelling evidence for the pathogenic role of Th17 in autoimmunity [51]. Th17 cells produce IL-17, a cytokine not produced by either Th1 or Th2 CD4+ T cells [52]. It has been confirmed that IL-17 is associated with inflammation, autoimmunity and host defense against some bacteria. Nonetheless, IL-17 has been implicated in many chronic autoimmune diseases including SLE [53], RA [54], MS [55], SS [56] and psoriasis [57]. Similar to IL-17, IL-22 is also highly expressed by Th17 cells. Recent findings have revealed that IL-22 is implicated in several autoimmune diseases. For example, IL-22 is differentially expressed in many autoimmune diseases [6, 7, 14]; IL-22 gene knockout or inhibition of IL-22 proteins could considerably ameliorate autoimmune diseases in many murine models $[58,59]$. However, most of these data do not determine whether IL-22 is mediating the inflammation itself, or is a by-product of the inflammation [60].

\subsection{SLE}

Systemic lupus erythematosus (SLE) is a systemic autoimmune disease, characterized by a multitude of autoantibody production, complement activation and immune-complex deposition, which causes tissue and organ damage. The etiology and pathogenic mechanisms of SLE have not yet been clearly elucidated. Cytokines produced by abnormal T-helper (Th) cells have been shown to be involved in the pathogenesis of SLE [51]. Although increased serum IL-22 production also has been found in several autoimmune diseases such as psoriasis and Crohn's disease (CD) [61, 62], in SLE patients, decreased serum and plasma IL-22 levels were observed by our groups and Cheng et al, respectively [6, 7]. The reason for this phenomenon is not known. Ziesché et al [8] have previously demonstrated that glucocorticoid dexamethasone (DEX) can suppress IL-22 production of plasma and PBMCs in the context of acute bacterial infections. This result may partially explain the decreased levels of serum IL-22 in SLE patients. However, McKinley et al [9] reported that IL-22 production were not sensitive to DEX treatment at any doses tested. Ziesché et al [8] suggest that those disparate observations may reflect diverse molecular mechanisms directing IL-22 production in the context of innate and adaptive immunity. The last result is in consistent with report by Cheng et al [7] in which it was reported that the cytokine levels were not associated with glucocorticoid treatment. However, in a later study, we found that the frequencies of IL-22-secreting CD4+ T cells were positively associated with glucocorticoid treatment. In addition, our data also displayed a similar relationship between glucocorticoid treatment and SLE disease activity index (SLEDAI) scores. There are several possible 
explanations for this phenomenon: first, the patients with duration of diagnosis for less than 2 months occupied a larger proportion, suggesting that these patients did not receive a longterm glucocorticoid treatment; second, patients with higher SLEDAI scores may receive a larger doses of glucocorticoids [10]. Furthermore, our data demonstrated that the increased frequencies of IL-22-positive CD4+ T cells have a positive correlation with SLEDAI score and lupus nephritis in patients with SLE, suggesting that this cytokine may be implicated in the pathogenesis of this disease. However, further studies are needed to clarify the precise mechanisms. More recently, a study by Yu et al reported that genetic variations in IL-22 copy numbers contribute to the risk of SLE, implicating that IL-22 in SLE risk might help to identify new targets for therapy. In addition, information about copy number variation (CNV) of this gene may help to define populations with high susceptibility to SLE [11]. Nevertheless, the exact mechanism of the role of IL-22 in the development and pathogenesis of SLE has not yet been elucidated. Therefore, further studies are needed to confirm these findings, and to explore the potential mechanisms involved and the therapeutic potential of IL-22 in SLE.

\subsection{RA}

Rheumatoid arthritis (RA) is a chronic, inflammatory, systemic autoimmune disorder that is characterized by symmetric inflammation of synovial joints, which leads to progressive joint destruction. Although RA has been the subject of innumerable investigations, the etiology and pathogenesis of the disease remain incompletely understood. It is clear, however, that cytokines play a key role in driving the synovial cell activation that leads to joint destruction. In RA, IL-22 is mainly expressed in synovial fibroblasts and macrophages, but only RA synovial fibroblasts, and not RA macrophages, have IL-22 receptor type I in the synovium. IL-22 promotes the proliferation of synovial fibroblasts and the production of monocyte chemoattractant protein 1 [12]. Geboes et al have investigated the role of IL-22 in collagen-induced arthritis (CIA), an animal model which shares many features with RA, and their results showed that IL-22 $2^{--}$mice were less susceptible to CIA than were wild-type mice, as evidenced by their decreased incidence of arthritis and reduced pannus formation. Remarkably, the less severe form of arthritis in IL-22-- mice was associated with increased production of type II collagen (CII)-specific and total IgG antibodies, whereas cellular CII responses were unchanged. In vitro, IL-22 was found to promote osteoclastogenesis, a process that might contribute to its proinflammatory activity in CIA [13]. In human RA, IL-22 is elevated in the serum of patients with established RA. Elevated serum IL-22 allows discrimination between patients with different clinical and laboratory measures and radiographic progression, indicating the potential of IL-22 as an additional tool for assessment of activity in RA, particularly in patients with RF antibodies and long-term disease $[14,15]$. Kim et al indicated that IL-22 promotes osteoclastogenesis in RA through induction of receptor activator of nuclear factor kappa-B ligand (RANKL) in human synovial fibroblasts [16].

\subsection{MS}

Multiple sclerosis (MS) is a chronic inflammatory demyelinating disorder of the central nervous system of unknown etiology, and represents the most common cause of nontraumatic neurological disability in young adults. Cytokine and cytokine receptor genes, 
including IL-2RA, IL-7R, IL-12A, etc. are appeared to be risk factors for MS [17].

However, disease heterogeneity and low tissue accessibility hinder functional studies of established MS risk genes. For this reason, the MS model experimental autoimmune encephalomyelitis (EAE) is often used to study neuroinflammatory disease mechanisms. Through a combined approach including genetic and immunological investigation in an animal model and large-scale association studies of MS patients, Beyeen et al established IL-22RA2 as an MS risk gene [18]. However, another study by Kreymborg et al showed that IL-22 is expressed by Th17 cells in an IL-23-dependent fashion, but is not required for the development of EAE [19]. Therefore, this divergence needs to be further clarified.

\subsection{Psoriasis}

Psoriasis is a common chronic autoimmune skin disease of unknown cause that involves dysregulated interplay between immune cells and keratinocytes. IL-22 is a cytokine produced by the Th1, Th17, and Th22 subsets that are functionally implicated in the psoriatic pathology. Therefore, IL-22 might play an important role in psoriasis. Transgenic mice engineered to over-express IL-22 have an aberrant skin phenotype that resembles psoriasis [22]. The IL-22 transgenic pups are born with shiny and stiff skin and die several days post-birth. Histological analysis of the skin reveals epidermal thickening and that the dermal layer contains infiltrating macrophages. Using IL-22-deficient mice, Zheng et al showed that in the absence of IL-22, IL-23-mediated dermal inflammation was reduced [23]. Another group has also shown that IL-22 is inflammatory in a T-cell-mediated model of psoriasis. A very recent study also showed that IL-22 is required for psoriasis-like lesions in the mouse imiquimod model. In spite of its functional importance, IL-22 is probably not sufficient in triggering psoriasis by itself. In fact, IL-22 synergizes with other cytokines to form a cytokine network that orchestrates the progression of many different pathogenic features of psoriasis [63].

\subsection{SS}

SS is an autoimmune disease targeting the exocrine glands resulting in xerostomia/ keratoconjunctivitissicca. Lavoie et al examined the levels and clinical associations of IL-22 in SS. Results indicated that serum levels of IL-22 were significantly elevated in patients with SS compared to controls. In addition, the serum levels of IL-22 showed significant correlations with hyposalivation, anti-SSB, anti-SSA/SSB combined, hypergammaglobulinemia and rheumatoid factor. These data suggest that IL-22 plays a critical role in the development of SS, and further study is needed to examine its function in human SS [20]. Ciccia et al investigated the IL-22 expression in the salivary glands of patients with primary Sjögren's syndrome (pSS), their results showed that IL-22, IL-23 and IL-17 were significantly increased at both protein and mRNA levels in the inflamed salivary glands of patients with pSS. STAT3 mRNA and the tyrosine phosphorylated corresponding protein were also significantly increased in pSS, suggesting that, together with IL-17 and IL-23, IL-22 may play a pro-inflammatory role in the pathogenesis of pSS [21]. These two aforementioned studies provide important clues concerning the role of IL-22 in SS, however, further studies (such as the gene knockout approach) will be needed to determine the exact physiological and immunological impact of IL-22 on this disease.

Cytokine Growth Factor Rev. Author manuscript; available in PMC 2014 April 29. 


\section{IL-22, a double-edged sword}

In contrast to its inflammatory role in autoimmune diseases, IL-22 also plays a protective role in inflammation in other diseases. Several previous studies have shown that IL-22 is protective during hepatitis $[64,65]$. In hepatitis, the immune system is responsible for damaging hepatocytes leading to reduced liver function. IL-22-deficient mice are highly sensitive to this damage, which can be ameliorated by transfer of IL-22-expressing Th17 cells [64]. This suggests that IL-22 could serves as a protective molecule to counteract the destructive nature of the immune response to limit tissue damage. In a recent study by Feng et al [66], they demonstrated wild-type and IL-22 knockout mice were equally susceptible to cerulein-induced acute and chronic pancreatitis, whereas liver-specific IL-22 transgenic mice were completely resistant to cerulein-induced elevation of serum digestive enzymes, pancreatic necrosis and apoptosis, and inflammatory cell infiltration. Treatment of wild-type mice with recombinant IL-22 or adenovirus IL-22 significantly attenuated the severity of cerulein-induced acute and chronic pancreatitis. Mechanistically, they showed that the protective effect of IL-22 on pancreatitis was mediated via the induction of Bcl-2 and Bcl$\mathrm{X}(\mathrm{L})$, which bind to Beclin-1 and subsequently inhibit autophagosome formation to ameliorate pancreatitis. In summary, their results suggest that IL-22 attenuates ceruleininduced pancreatitis by inhibiting the autophagic pathway, IL-22 thus could be a promising therapeutic drug to treat pancreatitis. Wolk et al have investigated the possible role of systemic IL-22 in Crohn's disease (CD), a common, chronic, inflammatory bowel disease characterized by intestinal infiltration of activated immune cells and distortion of the intestinal architecture. In their studies, they administered IL-22 to healthy mice and found an up-regulation of LPS-binding protein (LBP), with blood levels reaching concentrations known to neutralize LPS. This systemic up-regulation was associated with increased hepatic but not renal or pulmonary LBP mRNA levels. IL-22 also enhanced the secretion of LBP in human primary hepatocytes and HepG2 hepatoma cells in vitro. This increase was mainly transcriptionally regulated and synergistic with that of other LBP inducers. In addition, elevated LBP levels were detected in CD patients and the mouse colitis model. Their data suggest that systemic IL-22 may contribute to the prevention of systemic inflammation provoked by LPS present in the blood of CD patients through its induction of hepatic LBP [28].

\section{IL-22 as a potential therapeutic for autoimmune diseases}

Due to its crucial roles in inflammation and proliferation cascade, IL-22 may have promise as a potential therapeutic for autoimmune diseases. Understanding molecular mechanisms driving IL-22, together with knowledge on the capacity of current immunosuppressive drugs to target this process, may open an avenue to novel therapeutic options. Experimental delivery of IL-22 in animal models has produced promising results for several autoimmune diseases. Using an autoimmune psoriasis model, Ma et al reported that the neutralization of IL-22 activity by IL-22antibodiesreduces the expression of inflammatory mediators by epithelial cells and keratinocytes as well as the recruitment and maintenance of inflammatory Th17 cells at the tissue site, indicating that IL-22 antagonism represents a promising therapeutic approach for the treatment of Th17-mediated inflammatory skin disorders in humans [67]. Another recent study also assessed the role of IL-22 in a mouse 
model with psoriasi form skin inflammation. At the macroscopic level, scaly skin lesions induced by daily applications of imiquimod in wild-type mice were almost totally absent in IL-22-deficient mice or in mice treated with a blocking anti-IL-22 antibody. At the microscopic level, IL-22-deficient mice showed a dramatic decrease in the development of pustules and a partial decrease in acanthosis. At the molecular level, the absence or inhibition of IL-22 strongly significantly decreased the expression level of chemotactic factors such as CCL3 and CXCL3 [68]. Similarly, using neutralizing anti-IL-22 antibodies, Marijnissen et al evaluated the potential for IL-22 depletion in an experimental arthritis model using mice deficient in the IL-1 receptor antagonist (IL-1 $\mathrm{Ra}^{--}$), and their results showed that anti-IL-22 treatment of IL-1 $\mathrm{Ra}^{-/}$mice significantly reduced the inflammation and bone erosion [69]. Anti-cytokine vaccination is an innovative strategy of targeted, active immunotherapy with potential application in autoimmune diseases [58]. Administration of an IL-22 DNA vaccine to rodents provides protection during experimental autoimmune myocarditis or hepatitis [70,71]. Ke et al reported that administration of small doses of IL-22 to experimental autoimmune uveitis (EAU) -susceptible mice significantly reduced the severity of EAU. In addition, mice treated with IL-22 generated decreased numbers of IFN- $\gamma(+)$ and IL-17(+) uveitogenic T cells, but increased numbers of Foxp3(+) regulatory T cells [59]. All these results suggest IL-22 as a potential therapeutic for autoimmune diseases.

\section{Conclusion}

Although much remains to be explored about roles of IL-22 in autoimmune diseases, a solid basis of data from in vitro and in vivo models is now accumulating to support the therapeutic potential of IL-22 in autoimmune diseases. With findings obtained in eventual studies, development of recombinant IL-22 engineered to last long in vivo, discovery of small chemical compounds that mimic IL-22 signaling for immunosuppression, and establishment of antagonistic as well as agonistic antibodies will contribute to the development of novel therapeutic approaches to manage autoimmune diseases. However, it should be noted that IL-22 has the pleiotropic function, in particular it has dual proinflammatory and anti-inflammatory nature, which is the biggest obstacle to developing therapeutics based on this molecule. Therefore, further studies are required, especially in human systems, to comprehensively explore the role of IL-22 in autoimmune diseases. Further understanding the function and regulation of IL- 22 would certainly be beneficial in the future in treatment of autoimmune diseases.

\section{Acknowledgments}

This work was supported by grants from the National Natural Science Foundation of China $(81102192,30830089)$, the Specialized Research Fund for the Doctoral Program of Higher Education of China (20113420120008), the Grants for Scientific Research of BSKY (No. XJ201014) from Anhui Medical University, as well as grants from the National Institute of Health (AR059103 and AI084359), ACR Within Our Reach Fund, Arthritis Foundation and Wright Foundation.

We thank Dr. David Brand from Research Service, Veterans Affairs Medical Center, Memphis; USA for his critical comment and English grammar edit. 


\section{References}

1. Chung Y, Yang X, Chang SH, Ma L, Tian Q, Dong C. Expression and regulation of IL-22 in the IL-17-producing CD4+ T lymphocytes. Cell Res. 2006; 16:902-907. [PubMed: 17088898]

2. Liang SC, Tan XY, Luxenberg DP, Karim R, Dunussi-Joannopoulos K, Collins M, et al. Interleukin (IL)-22 and IL-17 are coexpressed by Th17 cells and cooperatively enhance expression of antimicrobial peptides. J Exp Med. 2006; 203:2271-2279. [PubMed: 16982811]

3. Cella M, Fuchs A, Vermi W, Facchetti F, Otero K, Lennerz JK, et al. A human natural killer cell subset provides an innate source of IL-22 for mucosal immunity. Nature. 2009; 457:722-725. [PubMed: 18978771]

4. Duhen T, Geiger R, Jarrossay D, Lanzavecchia A, Sallusto F. Production of interleukin 22 but not interleukin 17 by a subset of human skin-homing memory T cells. Nat Immunol. 2009; 10:857-863. [PubMed: 19578369]

5. Trifari S, Kaplan CD, Tran EH, Crellin NK, Spits H. Identification of a human helper T cell population that has abundant production of interleukin 22 and is distinct from $\mathrm{T}(\mathrm{H})-17, \mathrm{~T}(\mathrm{H}) 1$ and T(H)2 cells. Nat Immunol. 2009; 10:864-871. [PubMed: 19578368]

6. Pan HF, Zhao XF, Yuan H, Zhang WH, Li XP, Wang GH, et al. Decreased serum IL-22 levels in patients with systemic lupus erythematosus. Clin Chim Acta. 2009; 401:179-180. [PubMed: 19046958]

7. Cheng F, Guo Z, Xu H, Yan D, Li Q. Decreased plasma IL22 levels, but not increased IL17 and IL23 levels, correlate with disease activity in patients with systemic lupus erythematosus. Ann Rheum Dis. 2009; 68:604-606. [PubMed: 19286907]

8. Ziesche E, Scheiermann P, Bachmann M, Sadik CD, Hofstetter C, Zwissler B, et al. Dexamethasone suppresses interleukin-22 associated with bacterial infection in vitro and in vivo. Clin Exp Immunol. 2009; 157:370-376. [PubMed: 19664145]

9. McKinley L, Alcorn JF, Peterson A, Dupont RB, Kapadia S, Logar A, et al. TH17 cells mediate steroid-resistant airway inflammation and airway hyperresponsiveness in mice. J Immunol. 2008; 181:4089-4097. [PubMed: 18768865]

10. Qin WZ, Chen LL, Pan HF, Leng RX, Zhai ZM, Wang C, et al. Expressions of IL-22 in circulating CD4+/CD8+ T cells and their correlation with disease activity in SLE patients. Clin Exp Med. 2011; 11:245-250. [PubMed: 21487830]

11. Yu B, Guan M, Peng Y, Shao Y, Zhang C, Yue X, et al. Copy number variations of interleukin-17F, interleukin-21, and interleukin-22 are associated with systemic lupus erythematosus. Arthritis Rheum. 2011; 63:3487-3492. [PubMed: 22038405]

12. Ikeuchi H, Kuroiwa T, Hiramatsu N, Kaneko Y, Hiromura K, Ueki K, et al. Expression of interleukin-22 in rheumatoid arthritis: potential role as a proinflammatory cytokine. Arthritis Rheum. 2005; 52:1037-1046. [PubMed: 15818686]

13. Geboes L, Dumoutier L, Kelchtermans H, Schurgers E, Mitera T, Renauld JC, et al. Proinflammatory role of the Th17 cytokine interleukin-22 in collagen-induced arthritis in C57BL/6 mice. Arthritis Rheum. 2009; 60:390-395. [PubMed: 19180498]

14. da Rocha LF Jr, Duarte AL, Dantas AT, Mariz HA, Pitta ID, Galdino SL, et al. Increased Serum Interleukin 22 in Patients with Rheumatoid Arthritis and Correlation with Disease Activity. J Rheumatol. 2012

15. Leipe J, Schramm MA, Grunke M, Baeuerle M, Dechant C, Nigg AP, et al. Interleukin 22 serum levels are associated with radiographic progression in rheumatoid arthritis. Ann Rheum Dis. 2011; 70:1453-1457. [PubMed: 21593004]

16. Kim KW, Kim HR, Park JY, Park JS, Oh HJ, Woo YJ, et al. Interleukin-22 promotes osteoclastogenesis in rheumatoid arthritis through induction of RANKL in human synovial fibroblasts. Arthritis Rheum. 2012; 64:1015-1023. [PubMed: 22034096]

17. Vandenbroeck K, Alvarez J, Swaminathan B, Alloza I, Matesanz F, Urcelay E, et al. A cytokine gene screen uncovers SOCS1 as genetic risk factor for multiple sclerosis. Genes Immun. 2012; 13:21-28. [PubMed: 21716315] 
18. Beyeen AD, Adzemovic MZ, Ockinger J, Stridh P, Becanovic K, Laaksonen H, et al. IL-22RA2 associates with multiple sclerosis and macrophage effector mechanisms in experimental neuroinflammation. J Immunol. 2010; 185:6883-6890. [PubMed: 21041731]

19. Kreymborg K, Etzensperger R, Dumoutier L, Haak S, Rebollo A, Buch T, et al. IL-22 is expressed by Th17 cells in an IL-23-dependent fashion, but not required for the development of autoimmune encephalomyelitis. J Immunol. 2007; 179:8098-8104. [PubMed: 18056351]

20. Lavoie TN, Stewart CM, Berg KM, Li Y, Nguyen CQ. Expression of interleukin-22 in Sjogren's syndrome: significant correlation with disease parameters. Scand J Immunol. 2011; 74:377-382. [PubMed: 21645026]

21. Ciccia F, Guggino G, Rizzo A, Ferrante A, Raimondo S, Giardina A, et al. Potential involvement of IL-22 and IL-22-producing cells in the inflamed salivary glands of patients with Sjogren's syndrome. Ann Rheum Dis. 2012; 71:295-301. [PubMed: 21979002]

22. Wolk K, Haugen HS, Xu W, Witte E, Waggie K, Anderson M, et al. IL-22 and IL-20 are key mediators of the epidermal alterations in psoriasis while IL-17 and IFN-gamma are not. J Mol Med (Berl). 2009; 87:523-536. [PubMed: 19330474]

23. Zheng Y, Danilenko DM, Valdez P, Kasman I, Eastham-Anderson J, Wu J, et al. Interleukin-22, a $\mathrm{T}(\mathrm{H}) 17$ cytokine, mediates IL-23-induced dermal inflammation and acanthosis. Nature. 2007; 445:648-651. [PubMed: 17187052]

24. Sabat R. IL-10 family of cytokines. Cytokine Growth Factor Rev. 2010; 21:315-324. [PubMed: 21112807]

25. Dumoutier L, Louahed J, Renauld JC. Cloning and characterization of IL-10-related T cell-derived inducible factor (IL-TIF), a novel cytokine structurally related to IL-10 and inducible by IL-9. J Immunol. 2000; 164:1814-1819. [PubMed: 10657629]

26. Wolk K, Sabat R. Interleukin-22: a novel T- and NK-cell derived cytokine that regulates the biology of tissue cells. Cytokine Growth Factor Rev. 2006; 17:367-380. [PubMed: 17030002]

27. Wolk K, Kunz S, Witte E, Friedrich M, Asadullah K, Sabat R. IL-22 increases the innate immunity of tissues. Immunity. 2004; 21:241-254. [PubMed: 15308104]

28. Wolk K, Witte E, Hoffmann U, Doecke WD, Endesfelder S, Asadullah K, et al. IL-22 induces lipopolysaccharide-binding protein in hepatocytes: a potential systemic role of IL-22 in Crohn's disease. J Immunol. 2007; 178:5973-5981. [PubMed: 17442982]

29. Zhou L, Lopes JE, Chong MM, Ivanov, Min R, Victora GD, et al. TGF-beta-induced Foxp3 inhibits $\mathrm{T}(\mathrm{H}) 17$ cell differentiation by antagonizing RORgammat function. Nature. 2008; 453:236-240. [PubMed: 18368049]

30. Veldhoen M, Hirota K, Westendorf AM, Buer J, Dumoutier L, Renauld JC, et al. The aryl hydrocarbon receptor links TH17-cell-mediated autoimmunity to environmental toxins. Nature. 2008; 453:106-109. [PubMed: 18362914]

31. Zhang N, Pan HF, Ye DQ. Th22 in inflammatory and autoimmune disease: prospects for therapeutic intervention. Mol Cell Biochem. 353:41-46. [PubMed: 21384158]

32. Eyerich S, Eyerich K, Pennino D, Carbone T, Nasorri F, Pallotta S, et al. Th22 cells represent a distinct human $\mathrm{T}$ cell subset involved in epidermal immunity and remodeling. J Clin Invest. 2009; 119:3573-3585. [PubMed: 19920355]

33. Simonian PL, Wehrmann F, Roark CL, Born WK, O'Brien RL, Fontenot AP. gammadelta T cells protect against lung fibrosis via IL-22. J Exp Med. 207:2239-2253. [PubMed: 20855496]

34. Guo H, Topham DJ. Interleukin-22 (IL-22) production by pulmonary Natural Killer cells and the potential role of IL-22 during primary influenza virus infection. J Virol. 84:7750-7759. [PubMed: 20504940]

35. Zenewicz LA, Flavell RA. Recent advances in IL-22 biology. Int Immunol. 23:159-163. [PubMed: 21393631]

36. Cupedo T, Crellin NK, Papazian N, Rombouts EJ, Weijer K, Grogan JL, et al. Human fetal lymphoid tissue-inducer cells are interleukin 17-producing precursors to RORC+ CD127+ natural killer-like cells. Nat Immunol. 2009; 10:66-74. [PubMed: 19029905]

37. Takatori H, Kanno Y, Watford WT, Tato CM, Weiss G, Ivanov, et al. Lymphoid tissue inducerlike cells are an innate source of IL-17 and IL-22. J Exp Med. 2009; 206:35-41. [PubMed: 19114665] 
38. Sonnenberg GF, Fouser LA, Artis D. Functional biology of the IL-22-IL-22R pathway in regulating immunity and inflammation at barrier surfaces. Adv Immunol. 2010; 107:1-29. [PubMed: 21034969]

39. Xie MH, Aggarwal S, Ho WH, Foster J, Zhang Z, Stinson J, et al. Interleukin (IL)-22, a novel human cytokine that signals through the interferon receptor-related proteins CRF2-4 and IL-22R. J Biol Chem. 2000; 275:31335-31339. [PubMed: 10875937]

40. Lejeune D, Dumoutier L, Constantinescu S, Kruijer W, Schuringa JJ, Renauld JC. Interleukin-22 (IL-22) activates the JAK/STAT, ERK, JNK, and p38 MAP kinase pathways in a rat hepatoma cell line. Pathways that are shared with and distinct from IL-10. J Biol Chem. 2002; 277:33676-33682. [PubMed: 12087100]

41. Dumoutier L, de Meester C, Tavernier J, Renauld JC. New activation modus of STAT3: a tyrosineless region of the interleukin-22 receptor recruits STAT3 by interacting with its coiled-coil domain. J Biol Chem. 2009; 284:26377-26384. [PubMed: 19632985]

42. Pickert G, Neufert C, Leppkes M, Zheng Y, Wittkopf N, Warntjen M, et al. STAT3 links IL-22 signaling in intestinal epithelial cells to mucosal wound healing. J Exp Med. 2009; 206:14651472. [PubMed: 19564350]

43. Tagoe C, Putterman C. JAK2 inhibition in murine systemic lupus erythematosus. Immunotherapy. 2012; 4:369-372. [PubMed: 22512630]

44. Jia Y, Jing J, Bai Y, Li Z, Liu L, Luo J, et al. Amelioration of experimental autoimmune encephalomyelitis by plumbagin through down-regulation of JAK-STAT and NF-kappaB signaling pathways. PLoS One. 2011; 6:e27006. [PubMed: 22066025]

45. Jiang Z, Li H, Fitzgerald DC, Zhang GX, Rostami A. MOG(35-55) i.v suppresses experimental autoimmune encephalomyelitis partially through modulation of Th17 and JAK/STAT pathways. Eur J Immunol. 2009; 39:789-799. [PubMed: 19224632]

46. Arumugam S, Thandavarayan RA, Veeraveedu PT, Giridharan VV, Soetikno V, Harima M, et al. Involvement of AMPK and MAPK signaling during the progression of experimental autoimmune myocarditis in rats and its blockade using a novel antioxidant. Exp Mol Pathol. 2012

47. Noubade R, Krementsov DN, Del Rio R, Thornton T, Nagaleekar V, Saligrama N, et al. Activation of p38 MAPK in CD4 T cells controls IL-17 production and autoimmune encephalomyelitis. Blood. 2011; 118:3290-3300. [PubMed: 21791428]

48. Cope AP, Feldmann M. Emerging approaches for the therapy of autoimmune and chronic inflammatory disease. Curr Opin Immunol. 2004; 16:780-786. [PubMed: 15511673]

49. Chatenoud L. Immune therapies of autoimmune diseases: are we approaching a real cure? Curr Opin Immunol. 2006; 18:710-717. [PubMed: 17011768]

50. Kunz M, Ibrahim SM. Cytokines and cytokine profiles in human autoimmune diseases and animal models of autoimmunity. Mediators Inflamm. 2009; 2009:979258. [PubMed: 19884985]

51. Pan HF, Ye DQ, Li XP. Type 17 T-helper cells might be a promising therapeutic target for systemic lupus erythematosus. Nat Clin Pract Rheumatol. 2008; 4:352-353. [PubMed: 18477998]

52. Aggarwal S, Ghilardi N, Xie MH, de Sauvage FJ, Gurney AL. Interleukin-23 promotes a distinct CD4 T cell activation state characterized by the production of interleukin-17. J Biol Chem. 2003; 278:1910-1914. [PubMed: 12417590]

53. Garrett-Sinha LA, John S, Gaffen SL. IL-17 and the Th17 lineage in systemic lupus erythematosus. Curr Opin Rheumatol. 2008; 20:519-525. [PubMed: 18698171]

54. van den Berg WB, Miossec P. IL-17 as a future therapeutic target for rheumatoid arthritis. Nat Rev Rheumatol. 2009; 5:549-553. [PubMed: 19798029]

55. Pollinger B. IL-17 producing T cells in mouse models of multiple sclerosis and rheumatoid arthritis. J Mol Med (Berl). 2012; 90:613-624. [PubMed: 22231742]

56. Mieliauskaite D, Dumalakiene I, Rugiene R, Mackiewicz Z. Expression of IL-17, IL-23 and their receptors in minor salivary glands of patients with primary Sjogren's syndrome. Clin Dev Immunol. 2012; 2012:187258. [PubMed: 22262980]

57. Girolomoni G, Mrowietz U, Paul C. Psoriasis: rationale for targeting IL-17. Br J Dermatol. 2012

58. Semerano L, Assier E, Boissier MC. Anti-cytokine vaccination: A new biotherapy of autoimmunity? Autoimmun Rev. 2012

Cytokine Growth Factor Rev. Author manuscript; available in PMC 2014 April 29. 
59. Ke Y, Sun D, Jiang G, Kaplan HJ, Shao H. IL-22-induced regulatory CD11b+ APCs suppress experimental autoimmune uveitis. J Immunol. 2011; 187:2130-2139. [PubMed: 21795593]

60. Zenewicz LA, Flavell RA. IL-22 and inflammation: leukin' through a glass onion. Eur J Immunol. 2008; 38:3265-3268. [PubMed: 19016525]

61. Schmechel S, Konrad A, Diegelmann J, Glas J, Wetzke M, Paschos E, et al. Linking genetic susceptibility to Crohn's disease with Th17 cell function: IL-22 serum levels are increased in Crohn's disease and correlate with disease activity and IL23R genotype status. Inflamm Bowel Dis. 2008; 14:204-212. [PubMed: 18022867]

62. Lo YH, Torii K, Saito C, Furuhashi T, Maeda A, Morita A. Serum IL-22 correlates with psoriatic severity and serum IL-6 correlates with susceptibility to phototherapy. J Dermatol Sci. 58:225227. [PubMed: 20418068]

63. Ouyang W. Distinct roles of IL-22 in human psoriasis and inflammatory bowel disease. Cytokine Growth Factor Rev. 2010; 21:435-441. [PubMed: 21106435]

64. Zenewicz LA, Yancopoulos GD, Valenzuela DM, Murphy AJ, Karow M, Flavell RA. Interleukin-22 but not interleukin-17 provides protection to hepatocytes during acute liver inflammation. Immunity. 2007; 27:647-659. [PubMed: 17919941]

65. Radaeva S, Sun R, Pan HN, Hong F, Gao B. Interleukin 22 (IL-22) plays a protective role in T cell-mediated murine hepatitis: IL-22 is a survival factor for hepatocytes via STAT3 activation. Hepatology. 2004; 39:1332-1342. [PubMed: 15122762]

66. Feng D, Park O, Radaeva S, Wang H, Yin S, Kong X, et al. Interleukin-22 ameliorates ceruleininduced pancreatitis in mice by inhibiting the autophagic pathway. Int J Biol Sci. 8:249-257. [PubMed: 22253568]

67. Ma HL, Liang S, Li J, Napierata L, Brown T, Benoit S, et al. IL-22 is required for Th17 cellmediated pathology in a mouse model of psoriasis-like skin inflammation. J Clin Invest. 2008; 118:597-607. [PubMed: 18202747]

68. Van Belle AB, de Heusch M, Lemaire MM, Hendrickx E, Warnier G, Dunussi-Joannopoulos K, et al. IL-22 is required for imiquimod-induced psoriasiform skin inflammation in mice. J Immunol. 2012; 188:462-469. [PubMed: 22131335]

69. Marijnissen RJ, Koenders MI, Smeets RL, Stappers MH, Nickerson-Nutter C, Joosten LA, et al. Increased expression of interleukin-22 by synovial Th17 cells during late stages of murine experimental arthritis is controlled by interleukin- 1 and enhances bone degradation. Arthritis Rheum. 2011; 63:2939-2948. [PubMed: 21618207]

70. Chang H, Hanawa H, Liu H, Yoshida T, Hayashi M, Watanabe R, et al. Hydrodynamic-based delivery of an interleukin-22-Ig fusion gene ameliorates experimental autoimmune myocarditis in rats. J Immunol. 2006; 177:3635-3643. [PubMed: 16951323]

71. Pan H, Hong F, Radaeva S, Gao B. Hydrodynamic gene delivery of interleukin-22 protects the mouse liver from concanavalin A-, carbon tetrachloride-, and Fas ligand-induced injury via activation of STAT3. Cell Mol Immunol. 2004; 1:43-49. [PubMed: 16212920]

\section{Biographies}

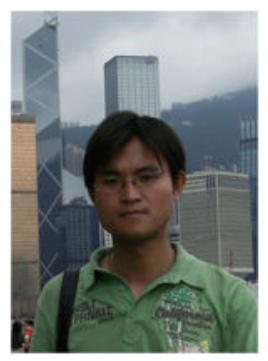

Hai-Feng Pan: M.D., assistant professor in the Department of Epidemiology and Biostatistics, School of Public Health, Anhui Medical University, China; the English Editor of the Chinese Journal of Disease Control \& Prevention; member of the Chinese Society for 
Immunology (CSI); current research interests: genetic epidemiology and pathogenesis of autoimmune diseases; publications: published more than 40 papers related to autoimmune disease in SCI Journal, including Nature Reviews Rheumatology, Cytokine and Growth Factor Reviews, Autoimmunity Reviews, Journal of Immunology, Arthritis \& Rheumatism, etc.

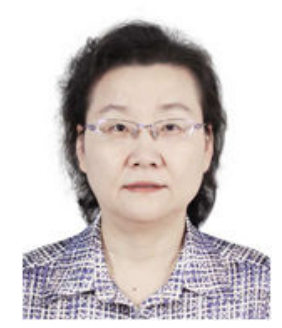

Xiang-Pei Li: A professor in Rheumatology, Chief physician, Doctor Tutor, Director of the Department of Rheumatology in Anhui Provincial Hospital, Hefei, China. Her scientific research is focused on the diagnosis, treatment and pathogenesis of rheumatic diseases; publications: published more than 40 papers related to rheumatic disease in SCI Journal, including Nature Reviews Rheumatology, Autoimmunity Reviews, Clinical Rheumatology, etc.

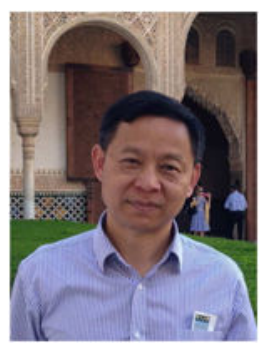

Song Guo Zheng: earned his M.D. at Anhui Medical University, M.S. at Fudan University Shanghai Medical School, and PhD at French National Center for Scientific Research and University of Orleans. He did his postdr studies at UCLA and University of Southern California (USC). He was appointed as Assistant Professor at USC in 2004 and is an Associate Professor and director of Immune Regulation and Tolerance Lab at USC now. Dr. Zheng and his colleagues discover TGF- $\beta$-induced regulatory T cells and focuses on the development and function of regulatory and effector $\mathrm{T}$ cells in autoimmunity.

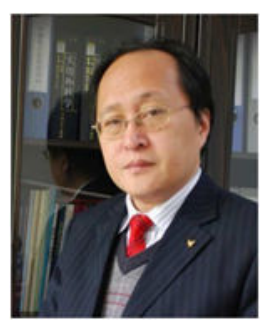

Dong-Qing Ye A professor in molecular Epidemiology; Doctor Tutor, Editor-in-Chief of Chinese Journal of Disease Control \& Prevention (CJDCP); Director of the Department of 
Epidemiology and Biostatistics, Anhui Medical University, China. His scientific research is focused on genetic and environmental factors related to systemic lupus erythematosus.

publications: published more than 100 papers related to autoimmune disease in SCI Journal, including Nature Genetics, PLoS Genetics, Nature Reviews Rheumatology, Autoimmunity

Reviews, Journal of Immunology, Arthritis \& Rheumatism, etc. 


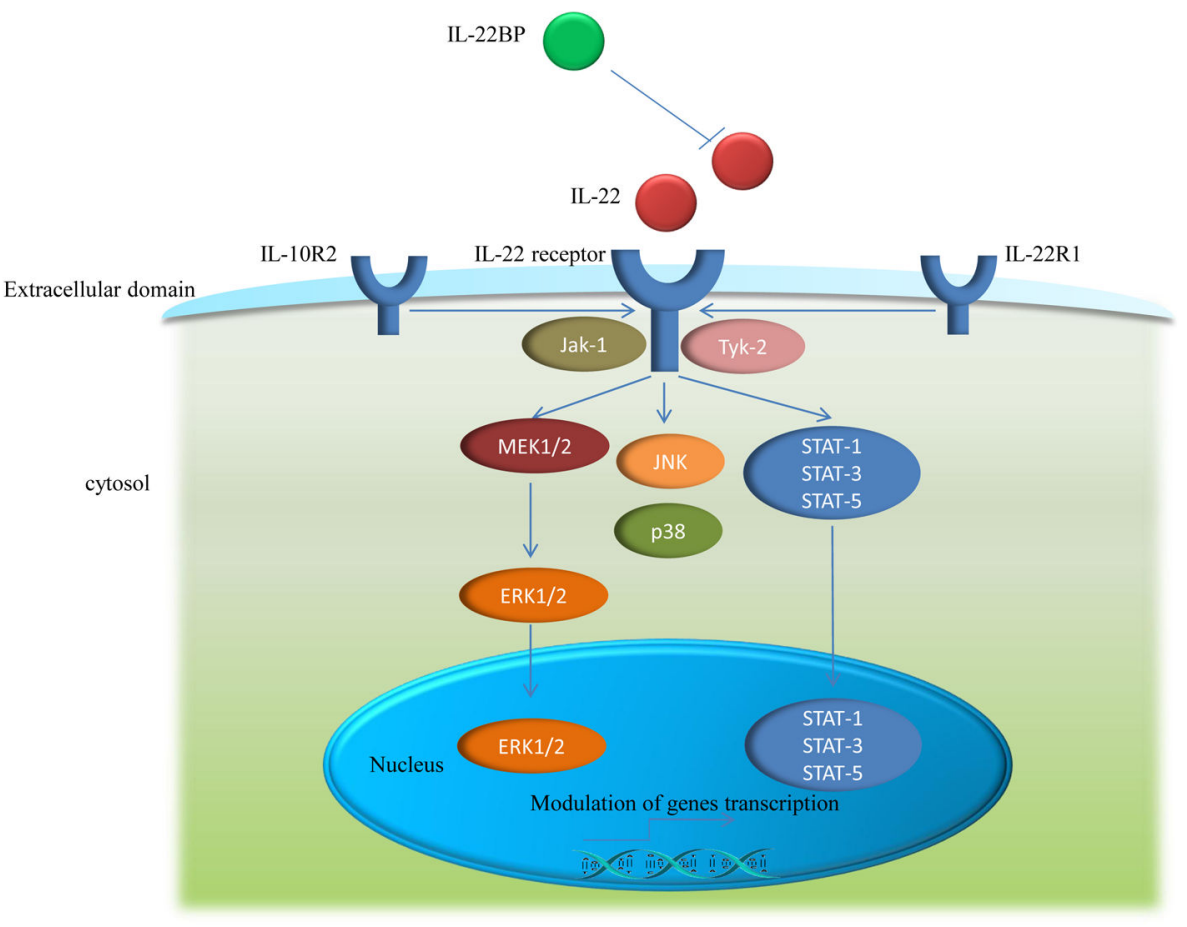

Figure 1. Signaling pathways of IL-22

IL-22 binds as a homodimer at a receptor complex composed of the IL-10R2 and the IL-22R1. IL-22BPacts as a natural, soluble antagonist. Receptor signaling induces the phosphorylation of Jak-1 and Tyk-2, which activates the transcription factor STAT1, and depending on the cell type, also STAT3 and STAT5. MAPKpathway (including MEK1/2, ERK1/2, JNK, and p38) are also activated through a distinct pathway. 


\section{Table 1}

The main cell resource of IL-22

\begin{tabular}{lll}
\hline Cell type & Transcription factor & Stimulating cytokine \\
\hline Th17 & RORC(Human) ROR $\gamma$ t(Mouse) & IL-6 \\
Th22 & AHR & IL-6 and TNF-a \\
$\gamma \delta$ T cells & ROR $\gamma$ t(Mouse) & IL-23 \\
NKT & ROR & IL-12 and IL-18 or IL-23 \\
LTi & RORC & IL-23 \\
\hline
\end{tabular}

